\title{
INDEX TO SURGICAL PROGRESS.
}

\section{GENERAL SURGERY.}

1. Gas Phlegmons. By Dr. A. Stolz (Strassburg). The object of this article is to subject to a critical review the organisms which are involved in the production of gas phlegmons. The conclusions are that the Welch-Frankel bacillus (an anaërobic non-motile butyric acid forming bacillus) is the main factor in producing a gas infection. Closely allied to it, though rarely encountered, is an anaërobic motile butyric acid bacillus described by Wicklein in three instances and encountered by the author once. It is doubtful whether in gas phlegmons we have any longer to reckon with the formerly recognized bacillus of malignant œdema.

Among the aërobic bacilli a number of undoubted Proteus vulgaris, hauseri, coli and paracoli infections were encountered, and on these occasions it was possible to demonstrate that these latter bacilli do not require the co-existence of diabetes. Finally, exceptional cases are reported that are traceable to other organisms, which will have to be reckoned with hereafter, dependent on accurate bacteriological data.-Beiträge zur klinischen Chirurgie, Band xxxiii, Heft I.

\section{THORAX.}

I. Pulmonary Embolism after Injuries and Operative Interference. By Dr. G. LotheISEN (Innsbruck). Lotheisen was able to collect sixty-one reported cases of pulmonary embolism with fifty-two deaths, representing a mortality of 83 per cent.

Following fractures, thirty-six instances are specified, occurring with equal frequency in both sexes between the ages of twenty-five and sixty-six, fractures of the leg being most repre- 
sented. Six instances are reported after contusions of thc abdomen and extremities, the male sex being favored; and four times subsequent to tendon and muscle ruptures.

Occurring after operative interference, sixteen cases are cited, five females, fifteen men, between the ages of seventeen and sixty-seven. Embolism occurred as early as twenty-four hours and as late as the fourth week. Embolism has an affinity for advanced years, no instances of its occurrence during infancy being reported. Women are particularly prone, as testified by the reports of gynæcologists, but in this summary males predominate. As a post-mortem finding, pulmonary embolism is more frequently encountered than in clinical reports, and, notwithstanding its rarity, itself is deserving of attention just because of its extremely sudden onset.

A particular disposition is favorable to embolism, thus anæmia incident to great loss of blood after uterine hæmorrhages, or after infectious diseases of long standing or cachexia, all are predisposing factors. The slowing of the blood current as the result of cardiac degeneration in alcoholics and pregnant women is likewise contributory to thrombosis. The thrombus which forms while the patient is recumbent is displaced with any strenuous movement upon arising. The diminution of intra-abdominal tension upon removal of fluids permits of a greater flow, whereby the thrombus can be displaced.

In view of the sudden onset of thrombosis, a sign foreboding its approach might be of value. Mahler describes a pulse-curve successively rising while the temperature remains low as being pathognomonic of impending embolism. Lotheisen does not give this his unqualified support, since an increase of pulse-rate often follows laparotomies from the manipulation of the bowel.

From a prophylactic stand-point it is conmendable to avoid operations during or after pregnancy, and when these are executed, the pelvis should be elevated, massage avoided, and all severe and violent motions forbidden. 
Embolism once at hand requires vigorous cardiac stimulation. -Beiträge zur klinischen Chirurgie, Band xxxii, Heft 3.

II. Decortication of the Lung in Chronic Empyema. By DR. KURPJWEIT (Königsberg). The author accords priority for this operation to George Ryerson Fowler. Preliminary to performing decortication, Delorme advises irrigation of the cavity with antiseptics for several days. Any pulmonary fistula must be sewn to obviate any subsequent pneumothorax.

The majority of operators do not make a trap-door incision as originally advocated by Delorme, but resect extensively, if necessary.

The results of the operation are set down by Delorme at $3^{\circ}$ per cent. to 40 per cent. cures. Cestan gives 40 per cent. cures, I I per cent. improved, 35 per cent. not improved, and I4 per cent. death. Fowler's report covered thirty cases,--seventeen cures, nine cases no cure, three deaths, and one doubtful. The interpretation of these combined statistics resolves itself into 35.7 per cent. cures, I9.7 per cent. improved, 33.9 per cent. no cure, Io per cent. death. In six deaths pulmonary tuberculosis was encountered.

The gaping of the incision of the divided thickened pleura is not due to the expansion of the lung beneath, but is due to the release of the thoracic tension which permits of a greater amplitude in thoracic excursion, which in turn tears the pulmonary pleura, and though the lung appears to expand under forced expiratory efforts, such as cough, it does not follow that the lung beneath the diseased pleura possesses spontaneous qualities of expanding. Permanent expansion is only possible if adhesions between the thoracic wall and lung ensue.

Where a trap-door flap is made, pneumothorax follows, which hinders the expansion of the lung. The approximation of the soft parts to the lung is necessary to enable the lung to expand. 
Delorme values the trap-door incision, since he claims it does not permanently deform the chest wall.

Compared with extensive resections, the statistics for the latter are $5^{6.3}$ per cent. cured, improved 20 per cent., no cure in three, death in twenty. For decortication there are but 33.9 per cent. cured.

In three instances only was the trap-door incision performed, wherefore the author is disposed to attribute much of the success to extensive resections of the ribs with adaptation of the soft parts to the lung.-Beiträge zur klinischen Chirurgie, Band xxxiii, Heft 3 .

\section{GENITO-URINARY ORGANS.}

I. Two Decades of Renal Surgery. By Dr. M. O. Wyss (Zurich). The author analyzes II3 operated cases from the stand-points of etiology, symptomatology, diagnosis, etc.

Etiology.-Traumatism may produce the most varied results. Its main interest centres in its producing but slight perirenal hæmorrhage, which in turn is capable of loosening the connective tissue and causing floating kidney, or, eventually, cicatrices that are likely to press upon the renal pedicle.

Hydronephrosis is always caused by a secondary pathologic factor that brings about obturation of the ureter, but this alone does not suffice. The author, supported by the observations of Israel and Landau, shows that still other factors must be active to effect hydronephrosis such as he sees in displacements of the kidney, which at the same moment affect the renal circulation in respect to its nutrition. Nephropexy permanently cured four cases of intermittent hydronephrosis.

In tuberculosis of the kidney heredity plays the usual rôle, particularly in the transmission from the father, whereas complication of other viscera was relatively seldom. The observation of fifteen operated cases showed no clinical evidence of systemic tuberculosis before operation, and because of the lasting cure 